\title{
DDAH2 mRNA expression is inversely associated with some cardiovascular risk-related features in healthy young adults
}

\author{
Blanca Puchau, Helen Hermana M. Hermsdorff, M. Ángeles Zulet and J. Alfredo Martínez* \\ Department of Nutrition and Food Science, Physiology and Toxicology, University of Navarra, Pamplona, Spain
}

\begin{abstract}
The purpose of this study was to evaluate whether the mRNA expression profiles of three genes (PRMT1, DDAH2 and NOS3) are related to ADMA metabolism and signalling, and the potential relationships with anthropometrical, biochemical, lifestyle and inflammatory indicators in healthy young adults. An emphasis on the putative effect of different mRNA expression on cardiovascular risk-related features was paid. Anthropometrical measurements as well as lifestyle features were analyzed in 120 healthy young adults. Fasting blood samples were collected for the measurement of glucose and lipid profiles as well as the concentrations of selected inflammatory markers. Profiles of mRNA expression were assessed for PRMT1, DDAH2 and NOS3 genes from peripheral blood mononuclear cells. Regarding inflammatory biomarkers, DDAH2 was inversely associated with IL-6 and TNF- $\alpha$. Moreover, subjects in the highest quintile of DDAH2 mRNA expression showed a reduced risk to have higher values of waist circumference, and to be more prone to show higher values of HDL-c. Interestingly, DDAH2 gene expression seemed to be related with some anthropometrical, biochemical, lifestyle and inflammatory indicators linked to cardiovascular risk in apparently healthy young adults, emerging as a potential disease marker.
\end{abstract}

Keywords: Protein arginine $N$-methyltransferase type I 1 (PRMT1), dimethylarginine dimethylaminohydrolase 2 (DDAH2), nitric oxide synthase 3 (NOS3), cardiovascular risk, asymmetric dimethylarginine (ADMA), atherosclerosis

\section{Introduction}

The role of inflammation and oxidative stress on several chronic diseases is receiving increasing attention due to the links with atherosclerosis, obesity and other chronic diseases $[1,2]$. Cause-effect relationships between these two defense processes (inflammation and oxidative stress) with disease are not clear, but several studies associate them with higher concentrations of inflammatory biomarkers [3-5]. In this sense, beyond its energy-storage function, adipose tissue is now recognised as a major endocrine organ synthesizing a variety of cytokines that play a role in inflammation [6,7], en-

* Corresponding author: J.A. Martínez, Department of Nutrition and Food Sciences, Physiology and Toxicology, University of Navarra. Calle Irunlarrea 1, 31008 Pamplona, Spain. Tel.: +34 948425600 ext. 6439; Fax: +34 948425619; E-mail: jalfmtz@unav.es. dothelial dysfunction [8] and vascular repair [9]. However, peripheral blood mononuclear cells have been used to study the proinflammatory state of adipocyte instead of using adipose tissue biopsies [10-12].

In this context, asymmetric dimethylarginine (ADMA) is a naturally occurring amino acid that inhibits the activity of nitric oxide synthase (NOS) [13], whose increase is related with endothelial dysfunction, which is in turn associated with several manifestations of cardiovascular disease [14]. As well as other cell types, peripheral blood mononuclear cells express the whole gene set that codes for the enzymatic system responsible for the biosynthesis and the degradation of ADMA, a methylarginine that is actually released by fat cells in culture [15]. The concerned enzymes include protein arginine N-methyltransferases type I (PRMTs) involved in ADMA synthesis [16,17], dimethylarginine dimethylaminohydrolases (DDAHs) responsible for ADMA degradation [18,19] as well as constitu- 
tive and inducible forms of NOS (i.e., NOS1, NOS2A and NOS3 genes), the main functional target of ADMA [15]. Since ADMA and its related pathways are sensitive to inflammation [15], their study in blood cells is a good target to better understand the early outcome of cardiovascular events. So, the aim of this study was to evaluate the mRNA expression profile of PRMT1, DDAH2 and NOS3 (genes related to ADMA metabolism and signalling) in relation with anthropometrical, biochemical, lifestyle and inflammatory indicators in healthy young adults, emphasizing on the putative effect of different mRNA expression on cardiovascular risk-related features as well as disease markers.

\section{Subjects, materials and methods}

\subsection{Subjects}

One hundred and twenty Caucasian healthy subjects were recruited to participate in the study (76 women and 44 men; age $20.9 \pm 2.5$ years). Initial enrolment screening evaluations included a medical history, physical examination and fasting blood profile, to exclude subjects with evidence of any disease related to chronic inflammation, oxidative stress, hydric unbalance, nutrient absorption or nutrient metabolism. Other exclusion criteria were chronic drug or nutritional treatments up to 6 months before the participation in this study. In accordance with the Declaration of Helsinki of the World Medical Association and, after a clear explanation of the study protocol, all subjects gave written informed consent to participate, which was previously reviewed and approved by the Ethics Committee of the University of Navarra (ref:79/2005).

\subsection{Anthropometrical and biochemical analyses}

All anthropometrical measurements were carried out with the subjects barefoot, wearing only their underwear and after an overnight fast following standarized protocols [20]. All these measurements were carried out three times, but not consecutively. Body weight was measured to the nearest $0.1 \mathrm{~kg}$ and body fat to the nearest $0.1 \%$ by using a Tanita TBF 300 (Tanita Corp., Tokyo, Japan). Body mass index (BMI) was calculated as body weight divided by squared height $\left(\mathrm{kg} / \mathrm{m}^{2}\right)$. Skinfold thicknesses (STs) were assessed at the right side to the nearest $0.2 \mathrm{~mm}$ by means of a Holtain skinfold caliper (Holtain, Crymych, UK) at the triceps, the biceps, subscapular and suprailiac. Percentage of truncal fat was calculated as the ratio between truncal (subscapular + suprailiac) and total STs (sum of biceps, triceps, subscapular, and suprailiac), expressed as a percentage as described elsewhere [21]. Waist circumference was measured with an inelastic tape to the nearest $1 \mathrm{~mm}$.

All serum blood samples were drew after an overnight (12-h) fast, centrifuged immediately for $15 \mathrm{~min}$ at $3500 \mathrm{rpm}$ and $4{ }^{\circ} \mathrm{C}$, and stored at $-80^{\circ} \mathrm{C}$. Serum glucose, triacylglycerols, total cholesterol and high-density lipoprotein cholesterol (HDL-c), were assessed by automatized colorimetric assays (COBAS MIRA, Roche, Switzerland) by using specific commercially available kits (ABX Pentra, Roche, Basel, Switzerland). The reported circulating low-density lipoprotein cholesterol (LDL-c) data were calculated by the Friedewald equation as described elsewhere [22]. Serum insulin concentrations were measured by using an enzyme-linked immunosorbent assay (ELISA) as described by the supplier (Mercodia, Uppsala, Sweden). For estimating insulin sensitivity [23], the homeostasis model assessment of insulin resistance (HOMAIR) was calculated as glucose concentration $\mathrm{x}$ insulin concentration/22.5. Plasma circulating concentrations of ADMA (DLD Diagnostika GmbH, Hamburg, Germany), CRP (Immundiagnostik AG, Bensheim, Germany), IL-6 (R\&D Systems, Minneapolis, MN, USA), TNF- $\alpha$ (R\&D Systems, Minneapolis, MN, USA) and PAI-1 (Diagnostica Stago, Asnières-surSeine, France) were evaluated by ELISA procedures. Plasma homocystein and serum ceruloplasmin concentrations were measured by a colorimetric and turbidimetric assays (COBAS MIRA, Roche, Switzerland) respectively by using commercially available kits (homocystein: Demeditec Diagnostics GmbH, Kiel-Wellsee, Germany; ceruloplasmin: ABX Pentra, Roche, Basel, Switzerland).

\subsection{Gene expression analyses}

Peripheral blood mononuclear cells were isolated by differential centrifugation $\left(450 \mathrm{~g}, 30 \mathrm{~min}\right.$, at $\left.20^{\circ} \mathrm{C}\right)$ by using PMN medium (Robbins Scientific Corporation, Sunnyvale, CA, USA). The peripheral blood mononuclear cells band was harvested with a Pasteur pipette and the cells were repeatedly washed with PBS [10]. The cell pellet was resuspended in Trizol reagent (Invitrogen Corporation, Carlsbad, CA, USA) and immediately frozen to $-80^{\circ} \mathrm{C}$ until RNA was extracted. The extraction of total RNA from peripheral blood mononu- 
clear cells was based on the Trizol reagent method according to manufacturer's instructions (Invitrogen Corporation, Carlsbad, CA, USA). Concentration of RNA and purity were assessed with a NanoDrop ND1000 spectrophotometer (Nanodrop, Wilmington, DE, USA) by absorbance at $\mathrm{UV}_{260}$ and $\mathrm{UV}_{260 / 280}$, respectively. Integrity of the RNA was verified by agarose gel electrophoresis. Extracted total RNA was purified with DNase treatment by means of DNA-free kit (Ambion/Applied Biosystems, Austin, TX, USA) used as a template to generate first-strand cDNA synthesis using M-MLV reverse transcriptase (Invitrogen Corporation, Carlsbad, CA, USA) as described by the supplier. Quantitative real-time PCR was performed by using an ABI PRISM 7000 HT Sequence Detection System as described by the manufacturer (Applied Biosystems, Foster City, CA, USA). Taqman probes for genes were also supplied by Applied Biosystems (Foster City, CA, USA). Gene expression levels were assessed and normalized by using 18s rRNA as internal control following previously described protocols [24,25].

\subsection{Statistical analyses}

The fold change (2-ddCt) in the target genes, normalized to $18 \mathrm{~S}$ and relative to the lowest expression profile, was calculated for each sample according to the manufacturer's guidelines (Applied Biosystems, Foster City, CA, USA). The Shapiro-Wilk test was used to determine variable distribution. Accordingly, the parametric Student's t test or nonparametric Mann-Whitney U test were performed to detect differences between low and high mRNA expression profiles of PRMT1 (cutoff: 3.6 arbitrary units), DDAH2 (cut-off: 4.5 arbitrary units) and NOS3 (cut-off: 4.6 arbitrary units). Partial correlation analyses were fitted to evaluate associations between variables after adjusting for sex, BMI, vitamin supplementation and family history of hypertension and obesity. Waist circumference and HDL-cholesterol were dichotomized for the logistic regression analysis using the median value as a cut-off. DDAH2 mRNA expression was distributed into quintiles for the logistic regression analysis to better understand its role in waist circumference and HDL-c prediction. The waist circumference model was adjusted for sex, BMI, smoking habits, previous weight loss and vitamin supplementation; the HDL-c model was adjusted for sex, BMI, smoking habits, previous weight loss, vitamin supplementation and physical activity. Results are presented as mean \pm standard deviation. Confidence intervals $(95 \% \mathrm{CI})$ were used to describe logistic regression's

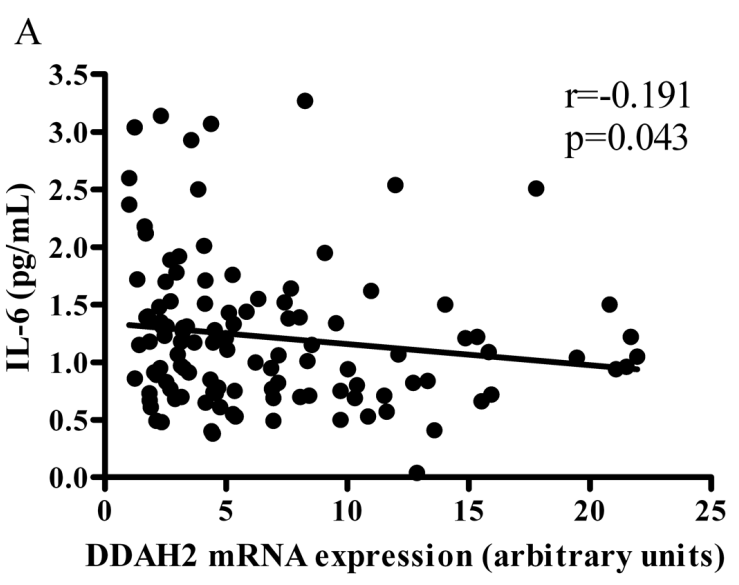

B

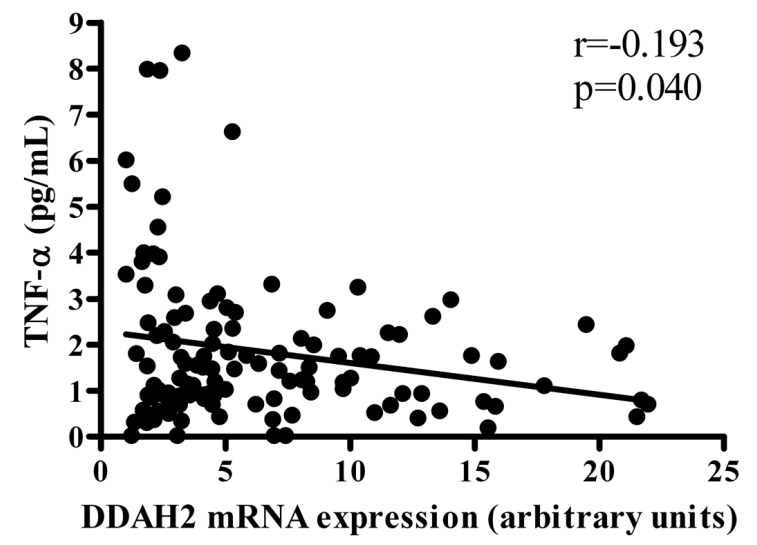

Fig. 1. Association between DDAH2 mRNA expression assessed in peripheral blood mononuclear cells and inflammation-related biomarkers: IL-6 (A) and TNF- $\alpha$ (B). Statistical analysis was performed by a partial correlation test after adjusting by sex, BMI, vitamin supplementation and family history of hypertension and obesity ( $n=120 ; r=-0.191$ and $p=0.043$ for IL-6; $r=-0.193$ and $p=0.040$ for TNF- $\alpha$ ). DDAH 2 mRNA expression was quantified as arbitrary units and refers to the fold change (2-ddCt) in the DDAH2 gene, normalized to $18 \mathrm{~S}$ and relative to the lowest expression profile.

odds ratio values, and $p<0.05$ was considered statistically significant. Statistical analyses were performed by using SPSS version 15.0 (SPSS Inc., Chicago, IL, USA) for Windows XP (Microsoft, Redmond, WA, USA).

\section{Results}

\subsection{Anthropometrical, biochemical and lifestyle data categorized according to ADMA-related gene expression}

Anthropometrical characteristics and biochemical determinations of subjects categorized according to 
Table 1

Anthropometrical and biochemical data (mean \pm SD) for young adults categorized by median of mRNA expression (arbitrary units) assessed in peripheral blood mononuclear cells. Cut-off values were 3.6, 4.5 and 4.6 arbitrary units for PRMT1 $(n=117)$, DDAH2 $(n=120)$ and NOS3 $(n=111)$, respectively

\begin{tabular}{|c|c|c|c|c|c|c|}
\hline & \multicolumn{2}{|c|}{ PRMT1 } & \multicolumn{2}{|c|}{ DDAH2 } & \multicolumn{2}{|c|}{ NOS3 } \\
\hline & $\begin{array}{c}\text { Low } \\
\text { expression }\end{array}$ & $\begin{array}{c}\text { High } \\
\text { expression }\end{array}$ & $\begin{array}{c}\text { Low } \\
\text { expression }\end{array}$ & $\begin{array}{c}\text { High } \\
\text { expression }\end{array}$ & $\begin{array}{c}\text { Low } \\
\text { expression }\end{array}$ & $\begin{array}{c}\text { High } \\
\text { expression }\end{array}$ \\
\hline Sex $(n$ males $(\%))$ & $23(36.5)$ & $20(37.0)$ & $23(39.0)$ & $21(34.4)$ & $22(37.9)$ & $17(32.1)$ \\
\hline Body mass index $\left(\mathrm{kg} / \mathrm{m}^{2}\right)$ & $22.1 \pm 2.8$ & $22.2 \pm 2.6$ & $22.2 \pm 2.9$ & $22.1 \pm 2.5$ & $22.0 \pm 2.9$ & $22.1 \pm 2.5$ \\
\hline Overweight $(n(\%))$ & $9(14.3)$ & $10(18.5)$ & $10(16.9)$ & $9(14.8)$ & $9(15.5)$ & $8(15.1)$ \\
\hline Waist circumference $(\mathrm{cm})$ & $73.5 \pm 9.0$ & $72.8 \pm 8.1$ & $74.7 \pm 9.3$ & $72.1 \pm 7.5$ & $73.1 \pm 9.1$ & $72.5 \pm 7.7$ \\
\hline Triceps skinfold (mm) & $15.2 \pm 4.9$ & $15.0 \pm 4.4$ & $15.0 \pm 5.0$ & $15.4 \pm 4.3$ & $15.0 \pm 5.3$ & $15.4 \pm 3.9$ \\
\hline Truncal fat (\%) & $54.1 \pm 8.2$ & $53.3 \pm 7.7$ & $55.0 \pm 8.4$ & $52.4 \pm 7.2$ & $53.9 \pm 8.4$ & $53.0 \pm 7.5$ \\
\hline Body fat (\%) & $19.4 \pm 6.9$ & $19.7 \pm 6.7$ & $19.2 \pm 6.9$ & $20.0 \pm 6.7$ & $19.2 \pm 7.8$ & $20.1 \pm 5.9$ \\
\hline Glucose $(\mathrm{mmol} / \mathrm{l})$ & $4.7 \pm 0.4$ & $4.7 \pm 0.5$ & $4.7 \pm 0.4$ & $4.7 \pm 0.4$ & $4.8 \pm 0.4$ & $4.7 \pm 0.4$ \\
\hline Insulin $(\mu \mathrm{UI} / \mathrm{ml})$ & $7.8 \pm 3.4$ & $8.2 \pm 3.6$ & $7.6 \pm 3.5$ & $8.3 \pm 3.5$ & $8.0 \pm 3.7$ & $7.7 \pm 3.2$ \\
\hline HOMA-IR & $1.6 \pm 0.7$ & $1.7 \pm 0.8$ & $1.6 \pm 0.7$ & $1.7 \pm 0.8$ & $1.7 \pm 0.8$ & $1.6 \pm 0.7$ \\
\hline Total cholesterol $(\mathrm{mmol} / \mathrm{l})$ & $4.6 \pm 0.7$ & $4.5 \pm 0.7$ & $4.5 \pm 0.6$ & $4.6 \pm 0.7$ & $4.4 \pm 0.7$ & $4.6 \pm 0.7$ \\
\hline HDL-c (mmol/l) & $1.5 \pm 0.3$ & $1.5 \pm 0.3$ & $1.5 \pm 0.3$ & $1.6 \pm 0.3$ & $1.5 \pm 0.4$ & $1.5 \pm 0.3$ \\
\hline LDL-c (mmol/l) & $2.7 \pm 0.6$ & $2.7 \pm 0.7$ & $2.7 \pm 0.6$ & $2.7 \pm 0.7$ & $2.6 \pm 0.6$ & $2.7 \pm 0.7$ \\
\hline Triacylglycerol (mmol/l) & $0.8 \pm 0.3$ & $0.8 \pm 0.3$ & $0.8 \pm 0.3$ & $0.7 \pm 0.3$ & $0.7 \pm 0.3$ & $0.8 \pm 0.3$ \\
\hline ADMA $(\mu \mathrm{mol} / 1) *$ & $0.53 \pm 0.27$ & $0.57 \pm 0.40$ & $0.53 \pm 0.29$ & $0.57 \pm 0.38$ & $0.51 \pm 0.23$ & $0.56 \pm 0.40$ \\
\hline
\end{tabular}

*PRMT1, $n=83 ;$ DDAH2, $n=84 ; \mathrm{NOS} 3, n=80$

Table 2

Lifestyle and family history data (mean $\pm \mathrm{SD}$ ) for young adults categorized by median of mRNA expression (arbitrary units) assessed in peripheral blood mononuclear cells. Cut-off values were 3.6, 4.5 and 4.6 arbitrary units for PRMT1 $(n=117)$, DDAH2 $(n=120)$ and NOS3 $(n=111)$, respectively

\begin{tabular}{|c|c|c|c|c|c|c|}
\hline & \multicolumn{2}{|c|}{ PRMT1 } & \multicolumn{2}{|c|}{ DDAH2 } & \multicolumn{2}{|c|}{ NOS3 } \\
\hline & $\begin{array}{c}\text { Low } \\
\text { expression }\end{array}$ & $\begin{array}{c}\text { High } \\
\text { expression }\end{array}$ & $\begin{array}{c}\text { Low } \\
\text { expression }\end{array}$ & $\begin{array}{l}\text { High } \\
\text { expression }\end{array}$ & $\begin{array}{c}\text { Low } \\
\text { expression }\end{array}$ & $\begin{array}{c}\text { High } \\
\text { expression }\end{array}$ \\
\hline Vitamin supplementation users $(n ; \%)$ & $20(31.7)$ & $19(35.2)$ & $22(37.3)$ & $17(27.9)$ & $18(31.0)$ & $19(35.8)$ \\
\hline Smokers $(n ; \%)$ & $16(25.4)$ & $12(22.6)$ & $18(31.0)$ & $10(16.4)$ & $12(21.1)$ & $13(24.5)$ \\
\hline Smoking (cigarettes/d) & $2.6 \pm 4.8$ & $2.7 \pm 5.6$ & $3.1 \pm 5.4$ & $2.1 \pm 4.9$ & $2.7 \pm 4.7$ & $2.2 \pm 5.1$ \\
\hline Physical activity (h/week) & $28.4 \pm 12.3$ & $29.5 \pm 20.7$ & $30.2 \pm 14.9$ & $27.9 \pm 18.0$ & $27.7 \pm 12.7$ & $29.9 \pm 20.5$ \\
\hline Sedentary habits (h/week) & $77.8 \pm 22.1$ & $70.8 \pm 19.4$ & $79.7 \pm 22.1$ & $70.0 \pm 18.5^{*}$ & $80.3 \pm 23.0$ & $68.9 \pm 18.0^{*}$ \\
\hline Family history of hypertension $(n ; \%)$ & $13(21.0)$ & $13(24.5)$ & $11(19.0)$ & $16(26.7)$ & $12(20.7)$ & $15(29.4)$ \\
\hline Family history of obesity $(n ; \%)$ & $13(20.6)$ & $10(18.5)$ & $12(20.3)$ & $11(18.0)$ & $13(22.4)$ & $9(17.0)$ \\
\hline
\end{tabular}

$* P$ value $<0.05$ for Mann-Whitney U-test between low and high mRNA expression profiles.

Table 3

Circulating levels of inflammation-related markers (mean \pm SD) for young adults categorized by quintiles of DDAH2 mRNA expression (arbitrary units) assessed in peripheral blood mononuclear cells

\begin{tabular}{|c|c|c|c|c|c|c|}
\hline & \multicolumn{2}{|c|}{ PRMT1 } & \multicolumn{2}{|c|}{ DDAH2 } & \multicolumn{2}{|c|}{ NOS3 } \\
\hline & $\begin{array}{c}\text { Low } \\
\text { expression }\end{array}$ & $\begin{array}{c}\text { High } \\
\text { expression }\end{array}$ & $\begin{array}{c}\text { Low } \\
\text { expression }\end{array}$ & $\begin{array}{c}\text { High } \\
\text { expression }\end{array}$ & $\begin{array}{c}\text { Low } \\
\text { expression }\end{array}$ & $\begin{array}{c}\text { High } \\
\text { expression }\end{array}$ \\
\hline $\mathrm{CRP}(\mathrm{mg} / \mathrm{l})$ & $1.18 \pm 0.78$ & $1.04 \pm 0.79$ & $1.19 \pm 0.83$ & $1.03 \pm 0.73$ & $1.13 \pm 0.82$ & $1.08 \pm 0.78$ \\
\hline IL-6 (pg/ml) & $1.55 \pm 1.06$ & $1.03 \pm 0.53 *$ & $1.52 \pm 1.10$ & $1.08 \pm 0.55^{*}$ & $1.44 \pm 1.06$ & $1.10 \pm 0.57 \#$ \\
\hline TNF- $\alpha(\mathrm{pg} / \mathrm{ml})$ & $2.48 \pm 2.86$ & $1.39 \pm 0.82 \#$ & $2.13 \pm 1.98$ & $1.82 \pm 2.42$ & $2.54 \pm 2.83$ & $1.50 \pm 1.26^{*}$ \\
\hline PAI-1 (ng/ml) & $21.98 \pm 15.27$ & $23.75 \pm 12.17 \#$ & $22.54 \pm 15.07$ & $23.05 \pm 12.41$ & $22.05 \pm 14.99$ & $23.98 \pm 12.27 \#$ \\
\hline Ceruloplasmin (g/l) & $0.21 \pm 0.06$ & $0.21 \pm 0.06$ & $0.21 \pm 0.06$ & $0.21 \pm 0.06$ & $0.20 \pm 0.06$ & $0.22 \pm 0.07 \#$ \\
\hline Homocystein $(\mu \mathrm{mol} / \mathrm{l})$ & $10.88 \pm 3.86$ & $12.50 \pm 6.87$ & $11.10 \pm 4.16$ & $12.14 \pm 6.44$ & $11.85 \pm 5.84$ & $11.48 \pm 5.43$ \\
\hline
\end{tabular}

$* P$ value $<0.05$ for Mann-Whitney U-test between between low and high mRNA expression profiles.

$\# P$ value $<0.10$ for Mann-Whitney U-test between between low and high mRNA expression profiles.

PRMT1, DDAH2 and NOS3 median mRNA expression profiles are reported (Table 1). No one of the analyzed variables produced any statistically significant difference between groups following this categoriza- tion criterion. However, concerning the DDAH2 mRNA expression profile, interesting differential reducing trends were found for visceral fat depots measurements and cardiovascular risk factors such as BMI, percent- 
Table 4

Logistic regression analysis with DDAH2 mRNA expression (arbitrary units) assessed in peripheral blood mononuclear cells as an independent variable $(n=120)$

\begin{tabular}{lcc}
\hline & Odds ratio (Confidence Interval 95\%) & $P$ value \\
\hline Model 1 $1^{\mathrm{a}}$ : Waist circumference as a dependent variable & \\
Q1 DDAH2 mRNA expression & 0 (Ref.) & \\
Q2 DDAH2 mRNA expression & $0.151(0.017$ to 1.353$)$ & 0.091 \\
Q3 DDAH2 mRNA expression & $0.155(0.020$ to 1.234$)$ & 0.078 \\
Q4 DDAH2 mRNA expression & $0.086(0.009$ to 0.978$)$ & 0.031 \\
Q5 DDAH2 mRNA expression & $0.123(0.015$ to 0.989$)$ & 0.049 \\
Model 2 $:$ HDL-cholesterol as a dependent variable & \\
Q1 DDAH2 mRNA expression & 0 (Ref.) & \\
Q2 DDAH2 mRNA expression & $3.596(0.848$ to 15.259$)$ & 0.083 \\
Q3 DDAH2 mRNA expression & $2.272(0.535$ to 9.649$)$ & 0.266 \\
Q4 DDAH2 mRNA expression & $2.470(0.537$ to 11.358$)$ & 0.245 \\
Q5 DDAH2 mRNA expression & $4.572(1.093$ to 19.130$)$ & 0.037 \\
\hline
\end{tabular}

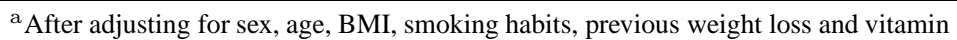
supplementation.

${ }^{\mathrm{b}}$ After adjusting for sex, age, BMI, smoking habits, previous weight loss, vitamin supplementation and physical activity.

age of overweight subjects, waist circumference, truncal vs. total STs (\% of truncal fat) and circulating triacylglycerol. Moreover, serum HDL-c seemed to be higher in subjects with higher profile of DDAH2 mRNA expression. Circulating ADMA levels did not show any change between low and high gene expression profiles. Regarding the analyzed lifestyle features (Table 2), only statistically significant changes in sedentary habits were detected between subjects with higher and lower DDAH 2 and NOS3 mRNA expression levels than the median (considered as the cut-off value). Furthermore, concerning the DDAH2 mRNA expression, smoking habits seemed to decrease in the upper expression group, although the difference did not achieve statistical significance. Interestingly, when adjusted for sex, BMI and vitamin supplementation, partial correlation analyses showed inverse associations between DDAH2 mRNA expression and smoking $(r=-0.21$; $p=0.038)$ and sedentary habits $(r=-0.24 ; p=$ $0.015)$.

\subsection{ADMA-related gene expression and inflammatory biomarkers}

On the other hand, differences in concentrations of clinically relevant inflammatory-related biomarkers (CRP, IL-6, TNF- $\alpha$, PAI-1, ceruloplasmina, homocystein) according low and high mRNA expression profiles were analyzed using the median as a cut-off value (Table 3). IL-6 showed to be statistically different according PRMT1 and DDAH2 mRNA expression, whereas TNF- $\alpha$ was statistically different only for NOS3 mRNA expression. The same trend was apparently fol- lowed for these two markers through all the expression profiles analyzed. To further investigate the relationship between the inflammatory-related markers and the mRNA expression of the target genes analyzed as continuous variables, partial correlation analyses were performed after adjusting for sex, BMI, vitamin supplementation, and family history of hypertension and obesity. Only inverse statistically significant correlations were found between DDAH2 mRNA expression and IL-6 and TNF- $\alpha$ circulating levels (Fig. 1).

\subsection{DDAH2 mRNA expression and cardiovascular risk}

To better understand the role of DDAH2 in cardiovascular risk-related features, a logistic regression analysis was performed (Table 4) showing that the highest quintile of DDAH2 mRNA expression seemed to be protective against higher values of waist circumference after adjusting for sex, age, BMI, smoking habits, previous weight loss and vitamin supplementation. Moreover, in a second logistic regression model, the highest quintile of DDAH2 mRNA expression was associated to higher serum HDL-c concentrations independently of sex, age, BMI, smoking habits, previous weight loss, vitamin supplementationa and physical activity.

\section{Discussion}

It has been described that ADMA concentrations were associated with obesity-related features [26] and that were higher in obese than in lean subjects [27]. 
However, although ADMA role understanding has been increasing during the last years, scarce information is available about its regulation at the gene expression level. So, in the present study, we have analyzed the role of gene expression of several enzymes linked to ADMA (PRMT1, DDAH2 and NOS3) in relation of anthropometrical, biochemical, lifestyle and inflammatory cardiovascular risk-related features.

In this study, gene expression analyses have been performed in peripheral blood mononuclear cells, which can be considered as a useful and non-invasive tool in order to determine the mechanisms involving obesity and related diseases [28]. Moreover, these cells have been used to study the proinflammatory state of adipocyte instead of using adipose tissue biopsies [1012].

The reported trends between low and high mRNA expression profiles of DDAH2 and BMI, percentage of overweight subjects, waist circumference and percentage of truncal fat suggest that DDAH2 expression may be related with visceral fat depots measurements. These findings are in agreement with previous studies concerning the expression of the enzymatic machinery for ADMA in different adiposity depots in healthy subjects [15]. In other human studies, a strong relationship between body mass index and plasma levels of ADMA in overweight subjects has been described [29]. Interestingly, weight reduction lowered ADMA values in morbidly obese women [30]. Moreover, in other studies ADMA values also correlated with triglycerides [27, 31]. Regarding the presence of ADMA and the expression of ADMA-related enzymes in adipocytes [32], and that the inhibition of NO release by synthetic NOS inhibitors in subcutaneous adipose tissue results in increased lipolysis in vivo [33], one could advance the hypothesis that ADMA would increase lipolysis, resulting in an augmented fatty acid flux eventually aggravating insulin resistance [32]. However, we did not find any association between ADMA-related gene expression in peripheral blood mononuclear cells and glucose metabolism, which may be explained by the different cell type. Concerning lifestyle features, it has been described that ADMA levels are not altered by exercise training [34], but nothing is reported about sedentary habits, for which we found an association with DDAH2 expression. In accordance with our results regarding DDAH2, ADMA concentrations and smoking habits, an association between ADMA levels and smoking status has been previously reported [29,31]. Although it was not statistically significant, subjects with a high mRNA expression of DDAH2 showed increased blood
ADMA concentrations (Table 1). The elevated levels of ADMA could be explained by a possible decrease in DDAH1 mRNA expression, as has been previously described in rats [35].

Since ADMA may be apparently linked to risk factors of obesity [27,29,30], type 2 diabetes [36], cardiovascular diseases [8,14,32,37] and several complications associated with low-grade inflammation and some inflammatory biomarkers [38,39], the possible associations between ADMA-related gene expression and inflammatory biomarkers should be of interest. In this sense, it has been described an increase on TNF- $\alpha$ levels due to exogenous ADMA administration [39], but nothing has been previously reported about this relationship at the gene expression level, in which we have found an inverse association between DDAH2 mRNA expression and TNF- $\alpha$ and IL-6 circulating levels. In this context, also a decrease in DDAH activity under exposure to TNF- $\alpha$ in cultured endothelial cells has been described [40].

The risk of acute coronary events is related to serum concentrations of ADMA in middle-aged men with normal renal function [41], and ADMA levels correlate positively with risk factors for atherosclerosis in subjects without vascular or renal disease [36]. Thus, dysregulation of DDAH has been proposed as a mechanism for endothelial dysfunction in individuals with hypercholesterolemia or atherosclerosis [42], which supports our findings, where a high expression profile of DDAH2 protects for high values of waist circumference, a typical cardiovascular risk factor, and is also associated with high values of the cardioprotective HDL-c.

Methyltransferase activity has been demonstrated for almost all PRMT genes [43]. However, we did not find any significant association with ADMA-related cardiovascular risk features. This can be due to the fact that PRMT1 is only one of the at least six type I PRMT isoforms (PRMT1, PRMT2, PRMT3, PRMT4, PRMT6 and PRMT8) [44], which are responsible for protein methylation [43]. On the other hand, the major metabolic pathway for ADMA is the enzyme DDAH [14]. Thus, a DDAH2 decrease leads to an increase of ADMA concentration [45], although we could not find such association in our sample. Furthermore, the substrate specificity of DDAH and its distribution in NO-generating systems gives support to the idea that regulating of intracellular ADMA levels by DDAH might in turn regulate NOS activity [43]. Of the two isoforms of DDAH, DDAH2 predominates in tissues that express endothelial NOS (NOS3), whose L-arginine binding site is blocked by ADMA by com- 
petitive inhibition mechanisms [13]. Furthermore, it is well known that ADMA exerts effects well beyond NOS3 control.

These results should be examined with care because of the reduced traslational size and the healthy characteristics of our young population. However, it can be con concluded that DDAH2 expression in peripheral blood mononuclear cells, but neither PRMT1 nor NOS3, seems to be related with anthropometrical, biochemical, lifestyle and inflammatory indicators linked to cardiovascular risk in apparently healthy young adults, which may constitute an early marker of disease risk.

\section{Acknowledgments}

This study is supported by the Línea Especial about Nutrition, Obesity and Health (LE/97), the Health Department of the Government of Navarra (22/2007), Ibercaja, The Capes Foundation of the Ministry of Education of Brazil (375605-0) and the ADA fellowships scheme of the University of Navarra. We thank Amaia González de Echávarri for her help with the recruitment and the data collection; Verónica Ciáurriz and Ana Lorente for technical assistance, Blanca Martínez de Morentin and Salomé Pérez for assistance with the data collection and all those who volunteered to participate in the study. The authors declare no conflict of interest in relation to this study.

\section{References}

[1] P. Brenneisen, H. Steinbrenner and H. Sies, Selenium, oxidative stress, and health aspects, Mol Aspects Med 26 (2005), 256-267.

[2] T. Fulop, D. Tessier and A. Carpentier, The metabolic syndrome, Pathol Biol (Paris) 54 (2006), 375-386.

[3] P. Dandona, A. Aljada and A. Bandyopadhyay, Inflammation: the link between insulin resistance, obesity and diabetes, Trends Immunol 25 (2004), 4-7.

[4] P. Dandona, A. Aljada, A. Chaudhuri, P. Mohanty and R. Garg, Metabolic syndrome: a comprehensive perspective based on interactions between obesity, diabetes, and inflammation, Circulation 111 (2005), 1448-1454.

[5] M.J. Moreno-Aliaga, J. Campión, F.I. Milagro, A. Berjón and J.A. Martinez, Adiposity and proinflammatory state: the chicken or the egg, Adipocytes 1 (2005), 1-16.

[6] P. Trayhurn and I.S. Wood, Adipokines: inflammation and the pleiotropic role of white adipose tissue, Br J Nutr 92 (2004), 347-355.

[7] C. Zoccali, F. Mallamaci and G. Tripepi, Adipose tissue as a source of inflammatory cytokines in health and disease: focus on end-stage renal disease, Kidney Int Suppl (2003), S65-S68.
[8] L.F. Van Gaal, I.L. Mertens and C.E. De Block, Mechanisms linking obesity with cardiovascular disease, Nature 444 (2006), 875-880.

[9] S.A. Ritchie, M.A. Ewart, C.G. Perry, J.M. Connell and I.P. Salt, The role of insulin and the adipocytokines in regulation of vascular endothelial function, Clin Sci (Lond) 107 (2004), 519-532.

[10] H. Ghanim, A. Aljada, D. Hofmeyer, T. Syed, P. Mohanty and P. Dandona, Circulating mononuclear cells in the obese are in a proinflammatory state, Circulation 110 (2004), 1564-1571.

[11] E. Goyenechea, D. Parra, A.B. Crujeiras, I. Abete and J.A. Martinez, A nutrigenomic inflammation-related PBMC-based approach to predict the weight-loss regain in obese subjects, Ann Nutr Metab 54 (2009), 43-51.

[12] N. Viguerie, H. Vidal, P. Arner, C. Holst, C. Verdich, S. Avizou, A. Astrup, W.H. Saris, I.A. Macdonald, E. Klimcakova, K. Clement, A. Martinez, J. Hoffstedt, T.I. Sorensen and D. Langin, Adipose tissue gene expression in obese subjects during low-fat and high-fat hypocaloric diets, Diabetologia 48 (2005), 123-131.

[13] R.H. Boger, The emerging role of asymmetric dimethylarginine as a novel cardiovascular risk factor, Cardiovasc Res $\mathbf{5 9}$ (2003), 824-833.

[14] J.P. Cooke, Does ADMA cause endothelial dysfunction? Arterioscler Thromb Vasc Biol 20 (2000), 2032-2037.

[15] B. Spoto, R.M. Parlongo, G. Parlongo, E. Sgro and C. Zoccali, The enzymatic machinery for ADMA synthesis and degradation is fully expressed in human adipocytes, J Nephrol $\mathbf{2 0}$ (2007), 554-559.

[16] S. Clarke, Protein methylation, Curr Opin Cell Biol 5 (1993), 977-983.

[17] N. Rawal, R. Rajpurohit, M.A. Lischwe, K.R. Williams, W.K. Paik and S. Kim, Structural specificity of substrate for $\mathrm{S}$-adenosylmethionine:protein arginine N-methyltransferases, Biochim Biophys Acta 1248 (1995), 11-18.

[18] M. Kimoto, G.S. Whitley, H. Tsuji and T. Ogawa, Detection of NG,NG-dimethylarginine dimethylaminohydrolase in human tissues using a monoclonal antibody, J Biochem 117 (1995), 237-238.

[19] T. Ogawa, M. Kimoto and K. Sasaoka, Occurrence of a new enzyme catalyzing the direct conversion of NG,NG-dimethylL-arginine to L-citrulline in rats, Biochem Biophys Res Commun 148 (1987), 671-677.

[20] R.S. Gibson, Principles of Nutritional Assessment, Oxford University Press, New York, 2005.

[21] J. Warnberg, E. Nova, L.A. Moreno, J. Romeo, M.I. Mesana, J.R. Ruiz, F.B. Ortega, M. Sjostrom, M. Bueno and A. Marcos, Inflammatory proteins are related to total and abdominal adiposity in a healthy adolescent population: the AVENA Study, Am J Clin Nutr 84 (2006), 505-512.

[22] W.T. Friedewald, R.I. Levy and D.S. Fredrickson, Estimation of the concentration of low-density lipoprotein cholesterol in plasma, without use of the preparative ultracentrifuge, Clin Chem 18 (1972), 499-502.

[23] D.R. Matthews, J.P. Hosker, A.S. Rudenski, B.A. Naylor, D.F. Treacher and R.C. Turner, Homeostasis model assessment: insulin resistance and beta-cell function from fasting glucose and insulin concentrations in men, Diabetologia 28 (1985), $412-419$.

[24] K.J. Livak and T.D. Schmittgen, Analysis of relative gene expression data using real-time quantitative PCR and the 2(Delta Delta C(T)), Method Methods 25 (2001), 402-408.

[25] F.I. Milagro, J. Campion and J.A. Martinez, 11-Beta hydroxysteroid dehydrogenase type 2 expression in white adipose 
tissue is strongly correlated with adiposity, J Steroid Biochem Mol Biol 104 (2007), 81-84.

[26] B. Puchau, M.A. Zulet, G. Urtiaga, I. Navarro-Blasco and J.A. Martinez, ADMA regulation by antioxidants intake in healthy young adults: a role as an early indicator of metabolic syndrome features, Metabolism (2009), DOI:10.1016/j.metabol.2009.04.037.

[27] E.B. Marliss, S. Chevalier, R. Gougeon, J.A. Morais, M. Lamarche, O. A. Adegoke and G. Wu, Elevations of plasma methylarginines in obesity and ageing are related to insulin sensitivity and rates of protein turnover, Diabetologia 49 (2006), 351-359.

[28] S. Debey, T. Zander, B. Brors, A. Popov, R. Eils and J.L. Schultze, A highly standardized, robust, and cost-effective method for genome-wide transcriptome analysis of peripheral blood applicable to large-scale clinical trials, Genomics $\mathbf{8 7}$ (2006), 653-664.

[29] H.M. Eid, H. Arnesen, E.M. Hjerkinn, T. Lyberg and I. Seljeflot, Relationship between obesity, smoking, and the endogenous nitric oxide synthase inhibitor, asymmetric dimethylarginine, Metabolism 53 (2004), 1574-1579.

[30] K. Krzyzanowska, F. Mittermayer, H.P. Kopp, M. Wolzt and G. Schernthaner, Weight loss reduces circulating asymmetrical dimethylarginine concentrations in morbidly obese women, $J$ Clin Endocrinol Metab 89 (2004), 6277-6281.

[31] A. Onat, G. Hergenc, G. Can and A. Karabulut, Serum asymmetric dimethylarginine levels among Turks: association with metabolic syndrome in women and tendency to decrease in smokers, Turk Kardiyol Dern Ars 36 (2008), 7-13.

[32] J.T. Kielstein and P.S. Tsao, From Zanius to ADMA: ADMA a new "adipocytokine" and its potential role in metabolic syndrome, J Nephrol 20 (2007), 515-517.

[33] K. Andersson, N. Gaudiot, C. Ribiere, M. Elizalde, Y. Giudicelli and P. Arner, A nitric oxide-mediated mechanism regulates lipolysis in human adipose tissue in vivo, Br J Pharmacol 126 (1999), 1639-1645.

[34] J. Niebauer, A.L. Clark, K.M. Webb-Peploe, R. Boger and A.J. Coats, Home-based exercise training modulates pro-oxidant substrates in patients with chronic heart failure, Eur J Heart Fail 7 (2005), 183-188.

[35] D. Wang, P.S. Gill, T. Chabrashvili, M.L. Onozato, J. Raggio, M. Mendonca, K. Dennehy, M. Li, P. Modlinger, J. Leiper, P. Vallance, O. Adler, A. Leone, A. Tojo, W.J. Welch and C.S. Wilcox, Isoform-specific regulation by $\mathrm{N}(\mathrm{G}), \mathrm{N}(\mathrm{G})$ dimethylarginine dimethylaminohydrolase of rat serum asymmetric dimethylarginine and vascular endothelium-derived re- laxing factor/NO, Circ Res 101 (2007), 627-635.

[36] H. Miyazaki, H. Matsuoka, J.P. Cooke, M. Usui, S. Ueda, S. Okuda and T. Imaizumi, Endogenous nitric oxide synthase inhibitor: a novel marker of atherosclerosis, Circulation 99 (1999), 1141-1146.

[37] M.I. Yilmaz, M. Saglam, K. Caglar, E. Cakir, A. Sonmez, T. Ozgurtas, A. Aydin, T. Eyileten, O. Ozcan, C. Acikel, M. Tasar, G. Genctoy, K. Erbil, A. Vural and C. Zoccali, The determinants of endothelial dysfunction in CKD: oxidative stress and asymmetric dimethylarginine, Am J Kidney Dis 47 (2006), 42-50.

[38] D. Konukoglu, S. Firtina and O. Serin, The relationship between plasma asymmetrical dimethyl-L-arginine and inflammation and adhesion molecule levels in subjects with normal, impaired, and diabetic glucose tolerance, Metabolism $\mathbf{5 7}$ (2008), 110-115.

[39] G.G. Zhang, Y.P. Bai, M.F. Chen, R.Z. Shi, D.J. Jiang, Q.M. Fu, G.S. Tan and Y.J. Li, Asymmetric dimethylarginine induces TNF-alpha production via ROS/NF-kappaB dependent pathway in human monocytic cells and the inhibitory effect of reinioside C, Vascul Pharmacol 48 (2008), 115-121.

[40] A. Fard, C.H. Tuck, J.A. Donis, R. Sciacca, M.R. Di Tullio, H. D. Wu, T. A. Bryant, N. T. Chen, M. Torres-Tamayo, R. Ramasamy, L. Berglund, H. N. Ginsberg, S. Homma and P. J. Cannon, Acute elevations of plasma asymmetric dimethylarginine and impaired endothelial function in response to a high-fat meal in patients with type 2 diabetes, Arterioscler Thromb Vasc Biol 20 (2000), 2039-2044.

[41] V.P. Valkonen, H. Paiva, J.T. Salonen, T.A. Lakka, T. Lehtimaki, J. Laakso and R. Laaksonen, Risk of acute coronary events and serum concentration of asymmetrical dimethylarginine, Lancet 358 (2001), 2127-2128.

[42] A. Ito, P.S. Tsao, S. Adimoolam, M. Kimoto, T. Ogawa and J.P. Cooke, Novel mechanism for endothelial dysfunction: dysregulation of dimethylarginine dimethylaminohydrolase, Circulation 99 (1999), 3092-3095.

[43] C.T. Tran, J.M. Leiper and P. Vallance, The DDAH/ADMA/ NOS pathway, Atheroscler Suppl 4 (2003), 33-40.

[44] C.D. Krause, Z.H. Yang, Y.S. Kim, J.H. Lee, J.R. Cook and S. Pestka, Protein arginine methyltransferases: evolution and assessment of their pharmacological and therapeutic potential, Pharmacol Ther 113 (2007), 50-87.

[45] C.W. Lu, Y. Xiong and P. He, Dimethylarginine dimethylaminohydrolase-2 overexpression improves impaired nitric oxide synthesis of endothelial cells induced by glycated protein, Nitric Oxide 16 (2007), 94-103. 


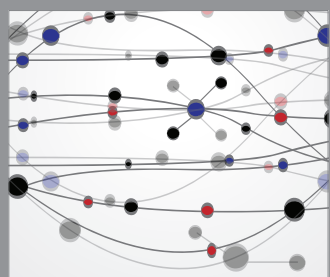

The Scientific World Journal
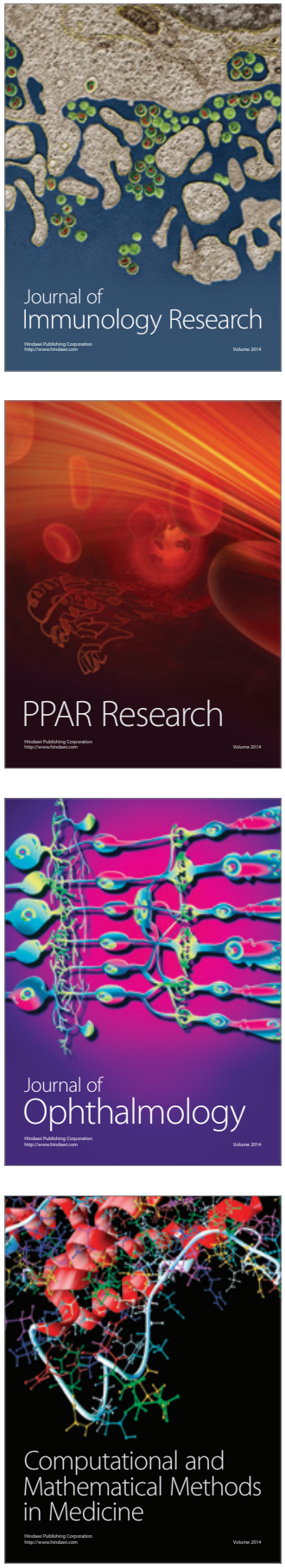

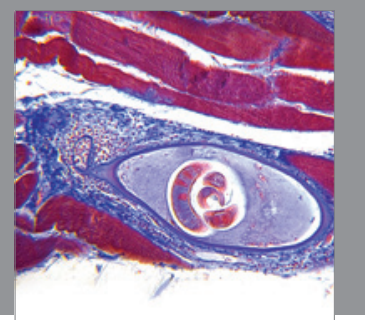

Gastroenterology

Research and Practice
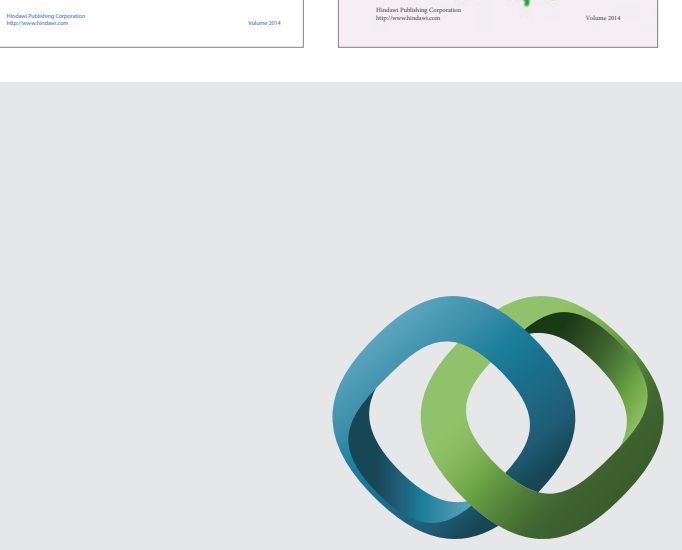

\section{Hindawi}

Submit your manuscripts at

http://www.hindawi.com
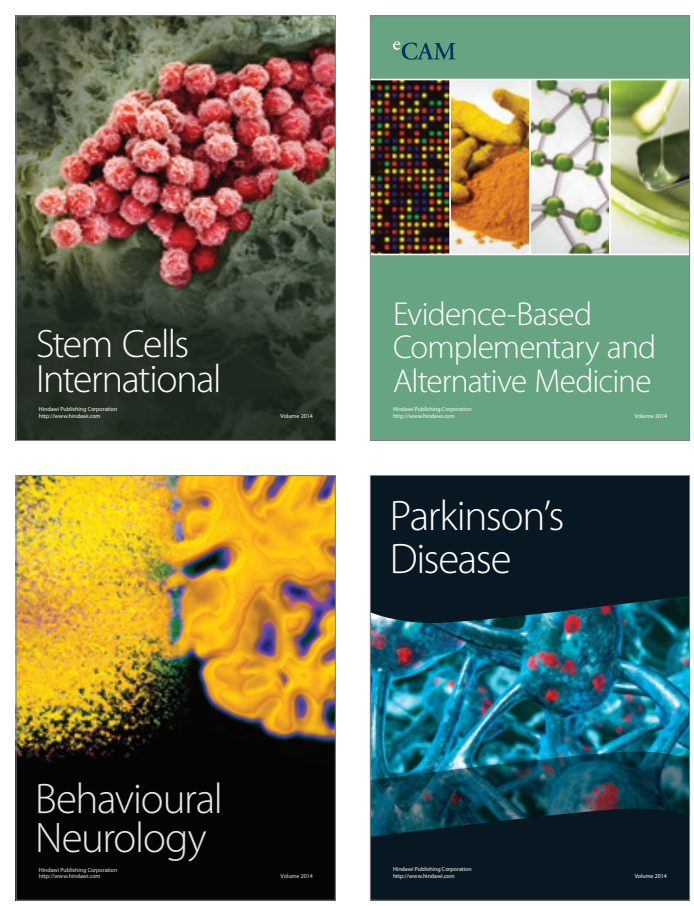

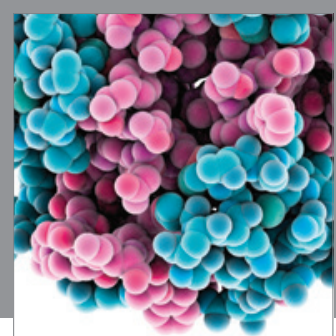

Journal of
Diabetes Research

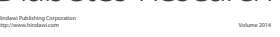

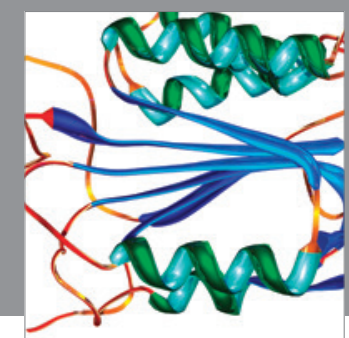

Disease Markers
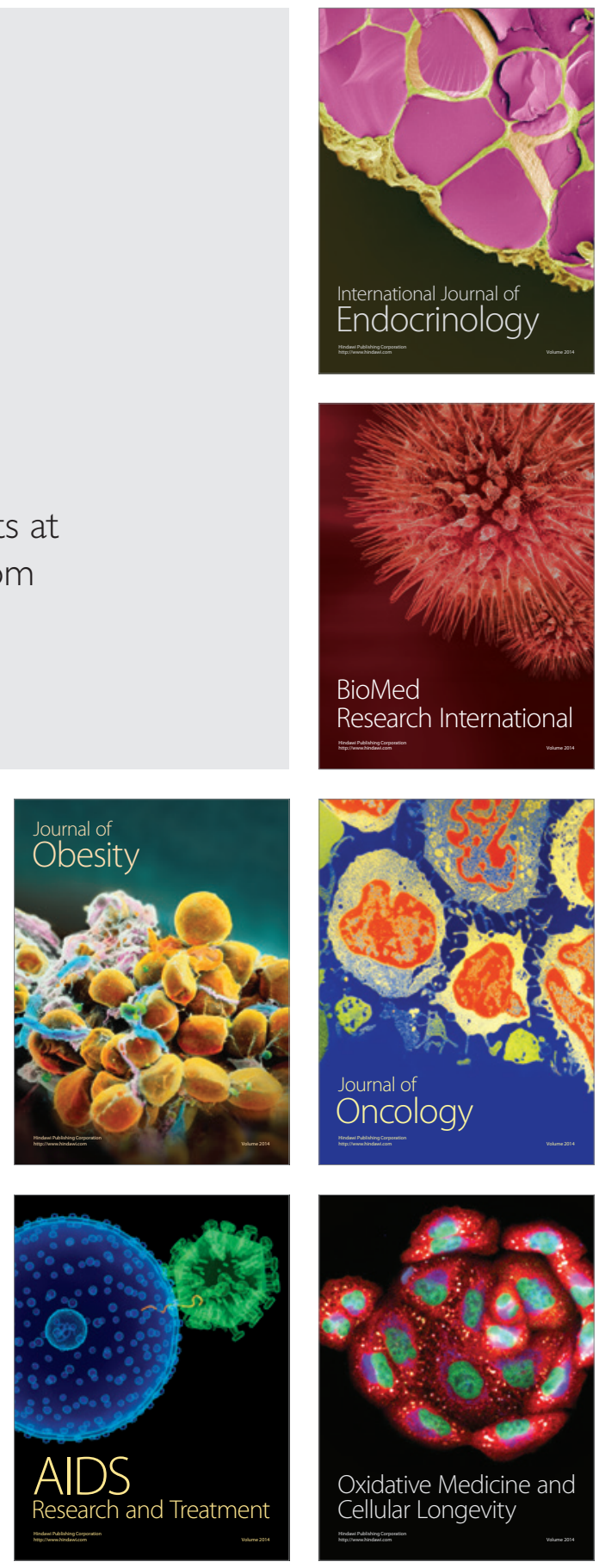